\title{
Model of Wound Healing for Esophagogastric Anastomoses in Rats
}

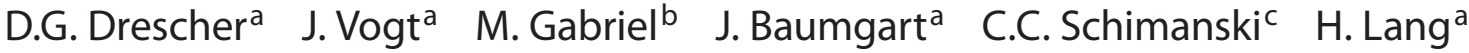 \\ I. Gockel ${ }^{\mathrm{a}}$ \\ Departments of a General and Abdominal Surgery and ${ }^{\mathrm{b}} \mathrm{Heart}$, Thoracic and Vascular Surgery, and \\ 'First Department of Internal Medicine, Johannes Gutenberg University of Mainz, Mainz, Germany
}

\section{Key Words}

Esophagogastric anastomosis - Gastric tube formation •

Anastomotic leakage $\cdot$ Wound healing

\begin{abstract}
Background: Anastomotic leakage after esophageal surgery is a significant cause of morbidity and mortality. Postoperative leakage of esophagogastric anastomosis has been reported in $2-30 \%$ of surgical patient, resulting in an increased need for reoperation and a high risk of subsequent esophageal stricture formation and fistula. So far, experimental investigations on major factors influencing the healing of esophageal anastomoses, e.g. neovascularization and collagen deposition, have been hindered by the lack of a functional rodent model. Methods: We developed a novel technique of gastric tube formation followed by end-to-end esophagogastric anastomosis in a rat model. Standardized anastomoses were carried out in 18 Brown-Norway rats and normal esophagogastric healing was studied by measuring anastomotic breaking strength 5 days after surgery. Results: Five animals showed an insufficiency of the esophagogastric anastomosis as determined by anastomotic leakage testing. Normal anastomotic healing was found in 10 animals. The anastomotic breaking strength was $1.93 \pm 0.45$ N. Conclusion: The rat model for performing esophagogastric anasto-
\end{abstract}

moses after gastric tube formation may serve as a functional and useful model in future research studies on microvascular and molecular processes of anastomotic healing.

Copyright $\odot 2012$ S. Karger AG, Basel

\section{Introduction}

Anastomotic leakage after esophagectomy is a disastrous complication bearing a high morbidity and mortality rate [1-4]. The organ frequently used for reconstruction after esophageal resection is the stomach $[1,5]$. When performing transhiatal esophagectomy, cervical esophagogastric anastomosis is required for reconstruction. After transthoracic esophagectomy, both, cervical and intrathoracic anastomoses are possible to be carried out. Some surgeons favor cervical esophagogastric anastomoses because of the reduced mortality and morbidity associated with cervical anastomotic leakage $[1,6]$.

This study was presented at the Deutscher Chirurgenkongress 2011, Munich, Germany (as a poster), at the Bayerischer Chirurgenkongress 2011, Munich, Germany (as an oral presentation), at the Viszeralmedizin 2011, Leipzig, Germany (as a poster) and at the Chirurgische Forschungstage 2011, Dresden, Germany (as an oral presentation).

\section{KARGER}

Fax +4161306 1234

E-Mail karger@karger.ch

www.karger.com
(C) 2012 S. Karger AG, Basel

0014-312X/12/0484-0194\$38.00/0

Accessible online at:

www.karger.com/esr
Daniel Drescher

Department of General and Abdominal Surgery

Johannes Gutenberg University of Mainz

Langenbeckstrasse 1, DE-55131 Mainz (Germany)

Tel. +49 613117 7291, E-Mail daniel.drescher@ unimedizin-mainz.de 

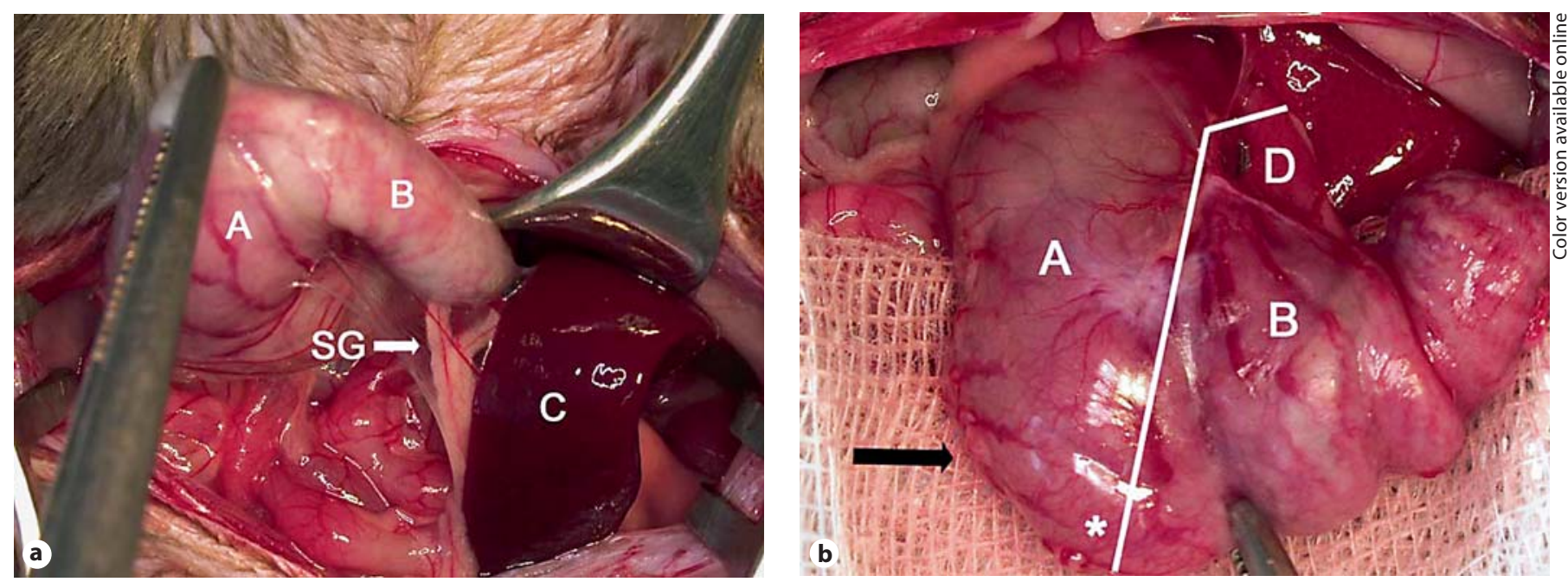

Fig. 1. a Gastrolysis: when performing dissection of the greater curvature along the gastric corpus (A) and forestomach (B), short gastric vessels (SG) between the stomach and the spleen (C) were clipped. b The right gastric and gastroepiploic arteries and veins (arrow) were preserved. Resection: the resection margin $\left(^{*}\right)$ starts $2 \mathrm{~mm}$ distal to the ending of the gastroepiploic arcade. The distal esophagus (D), the proximal lesser curvature and the forestomach $(B)$ were resected.

Compared to all other anastomoses of the gastrointestinal tract, anastomotic leakage of esophagogastric anastomosis is more frequent and has been reported in 2-30\% of patients [2, 7-9]. This significantly increases the need for reoperation and the risk of subsequent esophageal stricture formation and fistula $[9,10]$. The major factors influencing the healing of esophageal anastomoses are neoangiogenesis and collagen deposition $[11,12]$.

So far, experimental investigations on these factors have been hindered by the lack of a functional small animal model. Our aim was to develop a consistent and reliable rodent animal model for the performance of tubular gastroplasty and to facilitate experimental investigations on esophagogastric healing.

\section{Materials and Methods}

\section{Animals}

Animal experiments reported on in the present study conform to the guidelines for the care and use of laboratory animals, as established by the State Ethics Committee for Animal Experimentation (approval code: G 10-1-002). Thirty male Brown-Norway rats (mean weight: 320 g; Charles River, Sulzfeld, Germany) were allowed to become accustomed to laboratory conditions before experimental use. The animals were housed 1 per cage and were maintained at $21^{\circ} \mathrm{C}$ under 12 -hour light/12-hour dark cycles and specified pathogen-free conditions with free access to water and standard rodent food.

Esophagogastric Anastomoses in Rats

\section{Operative Procedures}

Prior to surgery, rats were fasted for $12 \mathrm{~h}$, but had unlimited access to water. After induction of anesthesia with isoflurane $(3 \%$ in an oxygen mixture, $31 / \mathrm{min}$ ) in a gas box, animals were kept under continuous isoflurane anesthesia (1.5\% in an oxygen mixture, $3 \mathrm{l} / \mathrm{min}$ ). Procedures were performed under sterile laboratory conditions, using a digital operation microscope (VHX600K, Keyence, Neu-Isenburg, Germany).

\section{Prestudies}

Prior to performing surgery in a standardized operative fashion, preliminary studies have been done in 12 animals to evaluate the optimal surgical technique and to define the time point for relaparotomy. The occurrence of anastomotic leakage was evaluated and controlled on the fifth and seventh postoperative day by relaparotomy and ex situ anastomotic leakage testing.

\section{Standardized Operative Technique and Procedures}

Standardized operative procedures were performed in 18 animals. Each animal was positioned supine and its abdomen was shaved and disinfected with Octenisept (Schülke, Norderstedt, Germany). Body temperature was maintained at $37^{\circ} \mathrm{C}$ using a heating lamp. In addition, $10 \mathrm{ml} 0.9 \% \mathrm{NaCl}$ was administered subcutaneously to prevent postoperative dehydration of the animals. Perioperative analgesia was performed with metamizole $110 \mathrm{mg} / \mathrm{kg}$ body weight. An upper median laparotomy was made and the peritoneal cavity was entered. Gastrolysis was carried out by dissection of the greater curvature of the stomach. Short gastric vessels and the left gastric artery and vein were clipped (fig. 1a). The right gastric and gastroepiploic arteries and veins were preserved. Dissection was continued towards the esophageal hiatus, and the abdominal esophagus was exposed. Gastric 

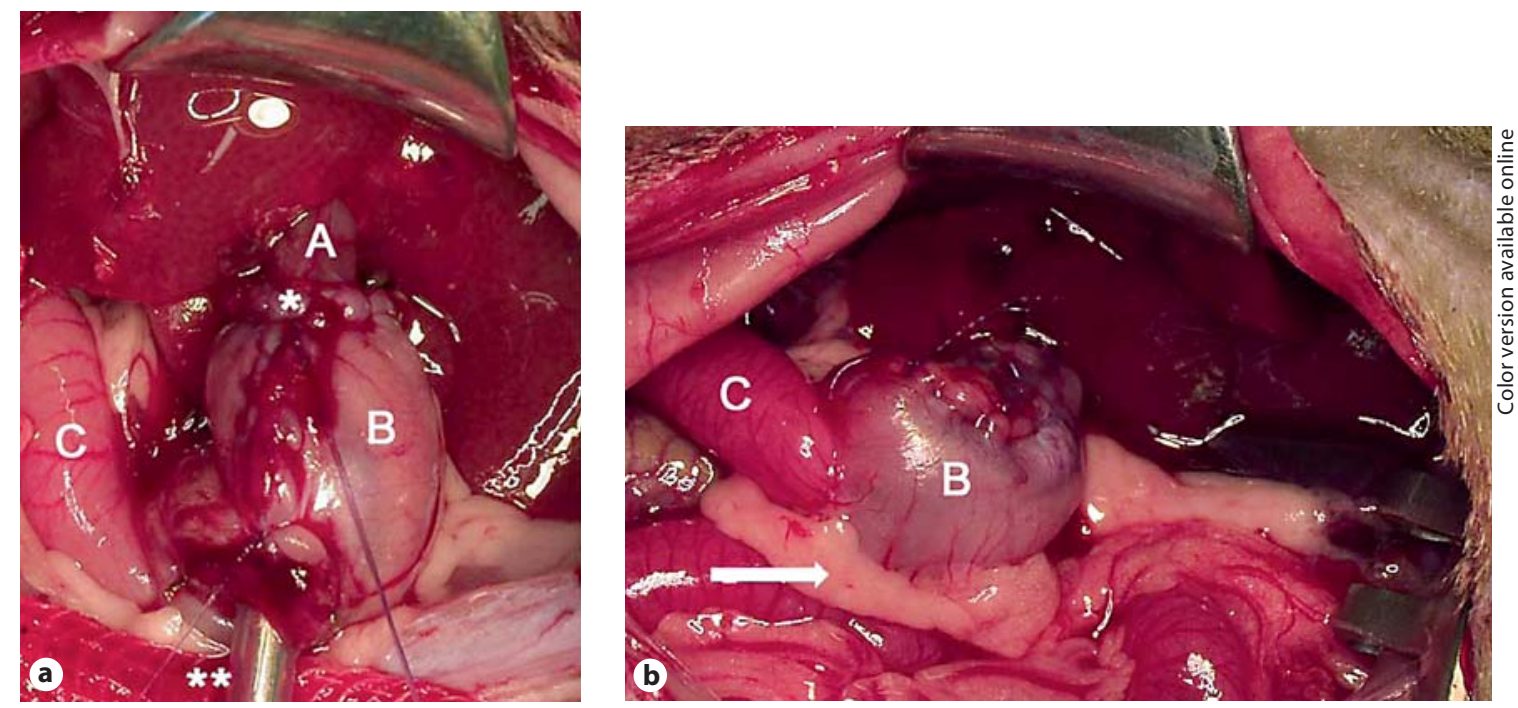

Fig. 2. a Reconstruction: the hand-sewn esophagogastric anastomosis $\left(^{*}\right)$ was performed after inserting a silicone catheter $\left({ }^{*}\right)$, proximal to the duodenum $(\mathrm{C})$, in the gastric tube $(\mathrm{B})$ and distal esophagus $(\mathrm{A})$. b The right gastric artery (arrow) is the single remaining artery, supplying the gastric tube.

Fig. 3. Schematic ex situ testing for anastomotic leakage: the duodenal lumen of the en bloc resected segment was attached to an infusion pump and perfused with saline solution. The digital manometer, connected to the esophageal lumen recorded the rise of pressure.

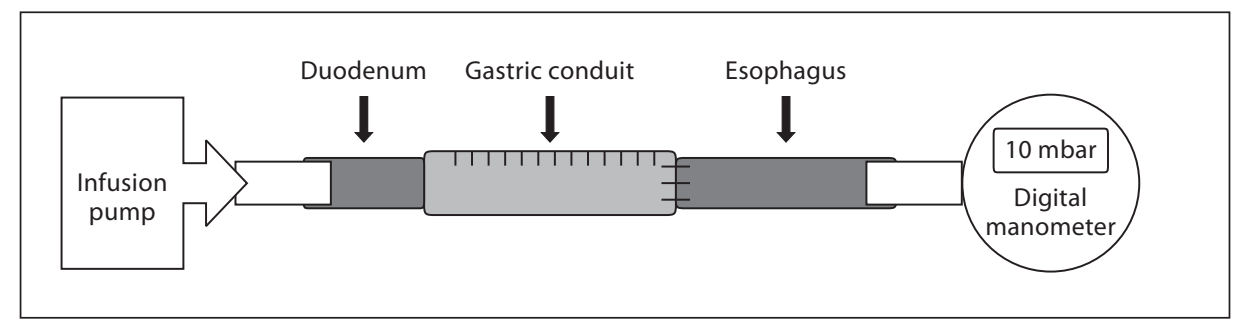

tube formation was performed after resection of the proximal lesser curvature, forestomach and the esophagogastric junction by using a continuous 7-0 PDS II (Ethicon, Norderstedt, Germany) suture (fig. 1b). A silicone catheter (diameter: $4 \mathrm{~mm}$ ) was inserted in the distal esophagus for calibrating the width of anastomosis, then the end-to-end intra-abdominal esophagogastric anastomosis was performed using a continuous 7-0 PDS II suture (Ethicon) (fig. 2a). After testing the anastomotic leak tightness, the catheter was removed and the gastric tube was closed. A lavage with $5 \mathrm{ml}$ warm saline solution was performed and the abdomen was closed, using a continuous 3-0 Vicryl suture (Ethicon) for the musculofascial layer and 4-0 Ethilon (Ethicon) for the skin. Postoperatively, the animals were allowed free cage activity and given water and milk (Aptamil Confort, Germany) ad libitum. Postoperative analgesia was performed with orally applied metamizole (100 mg per day). Animals were weighed daily and observed for signs of illness. All operative procedures were performed by the same surgeon.

On the fifth postoperative day, all surviving animals were euthanized by an anesthetic overdose. A relaparotomy was performed and the intra-abdominal aspects related to the preoperative surgical procedure were assessed, including the esophagogastric anastomosis and the gastric tube. The presence of inflam- mation, suture disruption and surrounding adhesions were also inspected. The esophagus, gastric tube and duodenum were carefully removed en bloc.

\section{Anastomotic Leakage Testing}

In order to test for anastomotic leakage, the duodenal lumen of the anastomotic segment was attached to an infusion pump by a silicone catheter with a diameter of $5 \mathrm{~mm}$ (Heidelberger Verlängerung, Braun, Melsungen, Germany) filled with saline solution (iso-osmolar, $0.9 \% \mathrm{NaCl}$ ). The esophageal lumen was connected to a digital manometer (Digital-Manometer GDH07AN; Greisinger Electronic, Germany). The segments were infused with saline solution $(2 \mathrm{ml} / \mathrm{min})$ to a maximum pressure of $10 \mathrm{mbar}$ and digitally monitored (fig. 3). Failure of pressure increase was determined as insufficiency and the site of leakage was noted.

\section{Anastomotic Breaking Strength Testing}

After testing for anastomotic leakage, the anastomotic segments were mounted in a tensiometer (Sauter FK25; Schumann, Sillerup, Germany) and distracted at $10 \mathrm{~mm} / \mathrm{min}$ (fig. 4). The breaking strength was digitally recorded in newton and the rupture site was noted. 
Fig. 4. Procedure for anastomotic breaking strength testing: the anastomotic segments were mounted in a tensiometer and distracted at $10 \mathrm{~mm} / \mathrm{min}$.

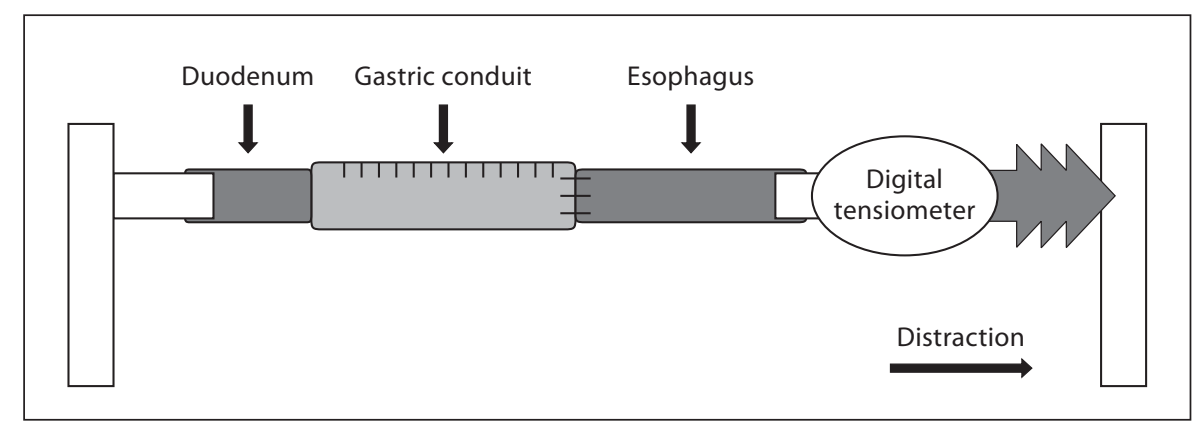

Fig. 5. Postoperative course and anastomotic testing procedures confirmed anastomotic leakage in 5 of 15 animals. At relaparotomy, 2 of these 5 animals did not show abdominal and perianastomotic pathologies. In these animals, only anastomotic leakage testing revealed insufficiency.

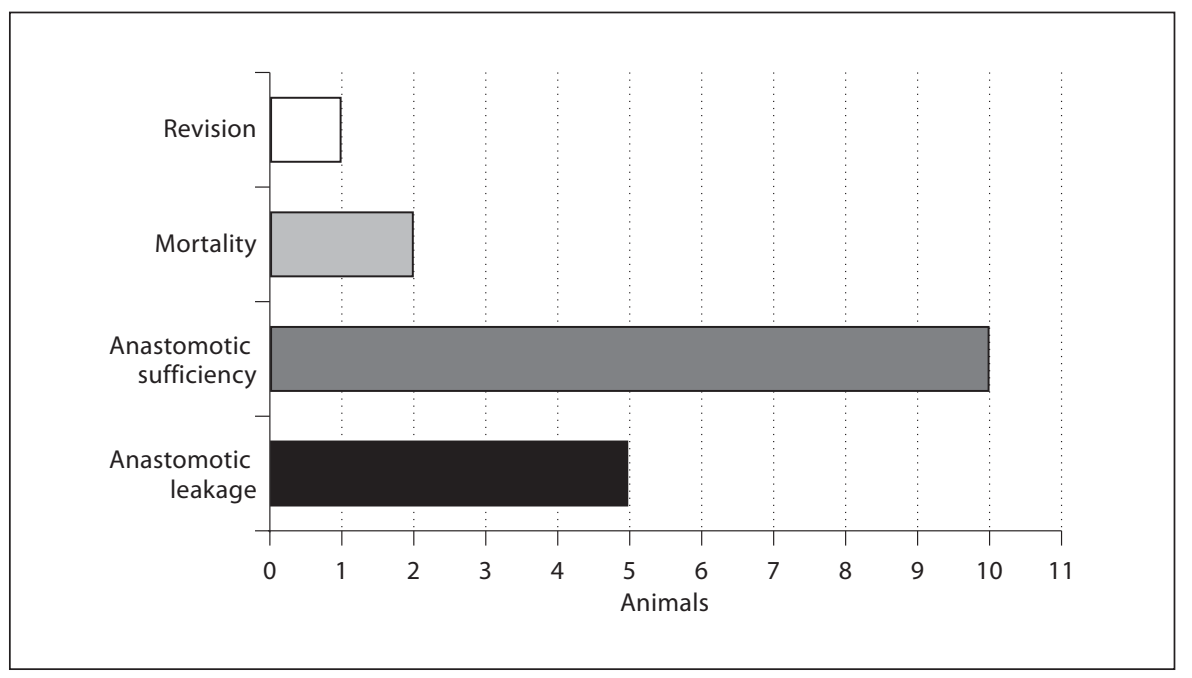

Statistical Analysis

Statistical analysis was performed with SPSS 13.0 for Microsoft Windows (SPSS Inc., Chicago, Ill., USA). Measured data are presented as means $\pm \mathrm{SD}$.

\section{Results}

\section{Perioperative Course}

Intraoperative deaths were not observed. The mean body weight on the fifth postoperative day was $302 \mathrm{~g}(6 \%$ weight loss). The overall mortality was $11 \%$. Two animals died on the third postoperative day of unknown causes. Necropsy did not reveal abdominal complications. One animal was revised on the third postoperative day because of illness and regurgitation. Abdominal exploration did not show any abdominal or anastomotic pathology as reason for illness. When testing the anastomosis for leakage, ex situ perfusion did not show insufficiency but anastomotic narrowing as cause of malnutrition and illness.

Planned relaparotomy on the fifth postoperative day was performed in 15 animals. Obvious signs of anasto- motic leakage were seen in 3 animals (20\%). Abdominal exploration showed anastomotic inflammation without peritonitis in 2 animals and perianastomotic microabscesses in a third animal. Two animals with no presence of abdominal and perianastomotic pathologies revealed anastomotic leakage by anastomotic leakage testing only (13\%) (fig. 5).

\section{Anastomotic Leakage Testing}

Five animals (33\%) showed an insufficiency of the esophagogastric anastomosis as determined by anastomotic leakage testing on the fifth postoperative day. An adequate rise of pressure was seen in 10 anastomotic segments (67\%).

\section{Anastomotic Breaking Strength Testing}

When performing measurement of anastomotic strength, the site of tissue disruption was always within the esophagogastric suture line. The anastomotic breaking strength was $1.93 \pm 0.45 \mathrm{~N}$ (range: $1.52 \mathrm{~N}$ ). 


\section{Discussion}

In the treatment of human esophageal malignancies, the gastric tube is a well-established conduit for esophageal replacement [1-8]. It is created from the greater curvature of the stomach and requires substantial gastric devascularization. After ligation of the left, right and short gastric vessels, the right gastroepiploic artery is the only remaining artery supplying the neoesophagus. Therefore, the blood supply of esophagogastric anastomosis depends on a sensible microscopic vascular network. However, anastomotic healing is a complex process involving various mechanisms, such as inflammation, neoangiogenesis, matrix synthesis and deposition, contraction and remodelling $[11,12]$. During the early postoperative period, anastomotic strength depends on a mature collagen matrix in the submucosal layer with a high suture-holding capacity and mechanical strength [12-14]. After surgery, synthesis of immature collagen occurs in the process of degrading polymerized collagen. Therefore, mechanical strength of the anastomosis relies upon the balance between lysis, synthesis, and maturation of collagen at the site of surgical injury [1214].

Extensive investigations in animal models, focusing on gastrointestinal anastomoses and evaluating agents that improve the anastomotic healing process, have been done. Small intestine and colonic anastomoses are simple to perform in rodents, as compared to esophagogastric anastomoses [15-17].

A major problem to investigate esophagogastric anastomotic healing in the rat is the very small esophageal lumen. Postoperative anastomotic narrowing causes dysphagia and malnutrition. The construction of a wide esophagogastric anastomotic lumen in rats promotes reflux and aspiration pneumonia. Therefore, some researchers handled this technical difficulties studying either esophageal or gastric wound healing as a surrogate for esophagogastric wound healing $[18,19]$ or used larger animals, such as pigs, cats and dogs [20-22]. Using a side-to-side technique for esophagogastric anastomosis results in a bigger anastomotic lumen and preservation of the normal esophagogastric route but does not respect the anatomic and vascular situation after gastric tube formation and reconstruction by esophagogastric anastomosis, as described before in a rat model [23]. Therefore, these approaches have obvious limitations.

In selecting an animal model to study esophagogastric anastomotic healing, to our mind it is a must to perform reconstruction analogous to that in humans after esophagectomy. Because of the gastric anatomic and vascular similarity to the human foregut and feasibility we chose rats. In our unique rat model, the length of the intra-abdominal esophagus facilitated distal esophageal resection and intra-abdominal reconstruction after gastric tube formation by end-to-end esophagogastric anastomosis. When performing intra-abdominal anastomosis the opening of the chest was not required and complications related to intrathoracic preparation could be prevented.

We developed a new technique of end-to-end esophagogastric anastomosis after distal esophagogastrectomy and gastric tube formation. In preliminary studies, the optimal anastomotic lumen diameter and occurrence of anastomotic leakage was evaluated and controlled on the fifth and seventh postoperative day by relaparotomy. Before the standardized, hand-sewn gastric and esophagogastric suture was performed, a silicone catheter with a diameter of $4 \mathrm{~mm}$ was inserted. As previously described for small bowel anastomoses in rats [24], in our studies also the broad gastric mucosal surface turned inside out and covered the resection margins of the stomach. The introduced catheter kept the small esophageal lumen opened, pushed back the gastric mucosal surface and facilitated the calibration of the anastomotic width. There was only 1 animal under standardized conditions with anastomotic narrowing leading to dysphagia and malnutrition. Because own previous investigations demonstrated that anastomotic leakage occurred between the fourth and fifth postoperative day, we defined this time point for planned relaparotomy and anastomotic testing procedures.

In our present study, anastomotic testing procedures confirmed anastomotic leakages in 5 of 15 animals (33\%). Remarkably, 2 of these 5 animals did not show abdominal and perianastomotic pathologies at relaparotomy and anastomotic leakage was revealed by anastomotic testing procedure only. Insufficiency, necrosis or narrowing of the gastric tube did not occur. When testing for anastomotic breaking strength, the site of tissue disruption was always within the esophagogastric suture line. The standardized ex situ testing procedures were reliable and showed an average breaking strength of $1.93 \pm 0.45 \mathrm{~N}$, which was within the expected range for esophagogastric anastomoses in rats $[19,23,25]$. 


\section{Conclusion}

Our unique rat model proved to be technically feasible in order to perform reconstruction by gastric tube formation and esophagogastric anastomosis analogous to that in humans after esophagectomy. This surgical technique facilitates further investigations on esophagogastric anastomotic healing, such as neoangiogenesis, matrix synthesis and tissue remodelling in a functional rodent model.

\section{Disclosure Statement}

There are no conflicts of interest or research funding concerning this study. Further, all authors disclose no sponsorship or financial arrangement relating to their research.

\section{References}

1 Walther B, Johansson J, Johnsson F, Holstein C, Zilling T: Cervical or thoracic anastomosis after esophageal resection and gastric tube reconstruction. Ann Surg 2003;238: 803-814.

$\longrightarrow 2$ van Heijl M, van Wijngaarden AK, Lagarde SM, Busch OR, van Lanschot JJ, van Berge Henegouwen MI: Intrathoracic manifestations of cervical anastomotic leaks after transhiatal and transthoracic oesophagectomy. Br J Surg 2010;97:726-731.

- 3 Crestanello JA, Deschamps C, Cassivi SD, Nichols FC, Allen MS, Schleck C, Pairolero PC: Selective management of intrathoracic anastomotic leak after esophagectomy. J Thorac Cardiovasc Surg 2005;129:254-260.

-4 Bruce J, Krukowski ZH, Al-Khairy G, Russell EM, Park KG: Systematic review of the definition and measurement of anastomotic leak after gastrointestinal surgery. Br J Surg 2001;88:1157-1168.

5 Urschel JD: Esophagogastrostomy anastomotic leaks complicating esophagectomy: a review. Am J Surg 1995; 169:634-640.

-6 Blewett CJ, Miller JD, Young JE, Bennett WF, Urschel JD: Anastomotic leaks after esophagectomy for esophageal cancer: a comparison of thoracic and cervical anastomoses. Ann Thorac Cardiovasc Surg 2001;7:75-78.

7 Okuyama M, Motoyama S, Suzuki H, Saito R, Maruyama K, Ogawa J: Hand-sewn cervical anastomosis versus stapled intrathoracic anastomosis after esophagectomy for middle or lower thoracic esophageal cancer: a prospective randomized controlled study. Surg Today 2007;37:947-952.

8 Yannopoulos P, Theodoridis P, Manes K: Esophagectomy without thoracotomy: 25 years of experience over 750 patients. Langenbecks Arch Surg 2009;394:611-616.
9 Dewar L, Gelfand G, Finley RJ, Evans K, Inculet R, Nelems B: Factors affecting cervical anastomotic leak and stricture formation following esophagogastrectomy and gastric tube interposition. Am J Surg 1992;163:484489.

10 van Heijl M, Gooszen JA, Fockens P, Busch OR, van Lanschot JJ, van Berge Henegouwen MI: Risk factors for development of benign cervical strictures after esophagectomy. Ann Surg 2010;251:1064-1069.

11 Stumpf M, Klinge U, Wilms A, Zabrocki R, Rosch R, Junge K, Krones C, Schumpelick V: Changes of the extracellular matrix as a risk factor for anastomotic leakage after large bowel surgery. Surgery 2005; 137:229-234.

12 Enestvedt CK, Thompson SK, Chang EY, Jobe BA: Clinical review: healing in gastrointestinal anastomoses. Part 2. Microsurgery 2006;26:137-143.

13 Jiborn H, Ahonen J, Zederfeldt B: Healing of experimental colonic anastomoses. 4. Effect of suture technique on collagen metabolism in the colonic wall. Am J Surg 1980;139:406413.

14 Thornton FJ, Barbul A: Healing in the gastrointestinal tract. Surg Clin North Am 1997;77:549-573.

15 Posma LAE, Bleichrodt RP, Lomme RMLM, de Man BM, van Goor H, Hendriks T: Early anastomotic repair in the rat intestine is affected by transient preoperative mesenteric ischemia. J Gastrointest Surg 2009;13:10991106.

16 De Ward JWD, Wobbes T, de Man BM, van der Linden CJ, Hendriks T: Post-operative levamisole may compromise early healing of experimental intestinal anastomoses. Br J Cancer 1995;72:456-460.

-17 Tadano S, Terashima H, Fukuzawa J, Matsuo $\mathrm{R}$, Ikeda O, Ohkohchi N: Early postoperative oral intake accelerates upper gastrointestinal anastomotic healing in the rat model. J Surg Res 2011;169:202-208.
18 Fedakar-Senyucel M, Bingol-Kologlu M, Vargun R, Akbay C, Sarac FN, Renda N, Hasirci N, Gollu G, Dindar H: The effects of local and sustained release of fibroblast growth factor on wound healing in esophageal anastomoses. J Pediatr Surg 2008;43:290-295.

19 Urschel JD, Takita H, Antkowiak JG: The effect of ischemic conditioning on gastric wound healing in the rat: implications for esophageal replacement with stomach. J Cardiovasc Surg 1997;38:535-538.

20 Schilling MK, Mettler D, Redaelli C, Buchler MW: Circulatory and anatomic differences among experimental gastric tubes as esophageal replacement. World J Surg 1997;21:992997.

21 Pearlstein L, Azneer IB, Polk HC Jr: An experimental assessment of esophageal anastomotic integrity. Surg Gynecol Obstet 1978; 146:545-550.

22 Gomes M, Ramacciotti E, Miranda F Jr, Henriques AC, Fagundes DJ: Vascular flow of the gastric fundus after arterial devascularization: an experimental study. J Surg Res 2009; 152:128-134.

23 Cui Y, Urschel JD, Petrelli NJ: Esophagogastric anastomoses in rats - an experimental model. J Invest Surg 1999;12:295-298.

24 Marjanovic G, Holzner P, Kulemann B, Kuesters S, Karcz WK, Timme S, Zur Hausen A, Baumann T, Hopt UT, Obermaier R, Hoeppner J: Pitfalls and technical aspects during the research of intestinal anastomotic healing in rats. Eur Surg Res 2010;45:314320 .

25 Urschel JD, Antkowiak JG, Delacure MD, Takita H: Ischemic conditioning (delay phenomenon) improves esophagogastric anastomotic wound healing in the rat. J Surg Oncol 1997;66:254-256. 